\title{
Walking as Method: Toward Methodological Forthrightness and Comparability in Urban Geographical Research
}

\author{
Joseph Pierce \\ Assistant Professor in the Department of Geography at The Florida State University, Tallahassee, FL 32306. \\ E-mail: jpierce3@fsu.edu. \\ His research interests include alternative urban development, sustainable urbanism, environmental justice, and the politics of place- \\ making.
}

\begin{abstract}
Mary Lawhon
Lecturer in the Department of Geography, Geoinformatics and Meteorology at the University of Pretoria, South Africa.

E-mail: marylawhon@gmail.com.

Her research interests include urban political ecology, waste politics, Southern theory, and the politics of sociotechnical transitions.
\end{abstract}

Qualitative urban geographical research should explicitly acknowledge insights gained from walking (the iterative exploration and observation of cities on foot), which enhances local literacy and enables researchers to compare methods more explicitly. Some urban geographers might use walking as a method, but it is rarely reported in published scholarship. This article argues for the explicit inclusion of walking in methodological reporting for urban research. We suggest that reporting the walking that researchers do adds rigor to research findings and should be distinguished from research where this practice is absent, we report on international experiences using walking in combination with other methods, and we conclude with a proposal for comparable urban geographic walking practices.

Key Words: qualitative methods, qualitative validity, urban geography, walking.

Urban geographers, particularly those employing qualitative methods, do a lot of wandering around cities

we study. We look at buildings, chat with shopkeepers, observe rush hour dynamics, ask passersby not-soinnocent questions about the bus ser-vice, and generally try to situate ourselves in the cities we are examining by participating in their pedestrian and vehicular flows. Although walking as method is rarely reported in contemporary scholarship, the prac-tice of walking is an important mode of geographical examination (Wylie 2005; Murphy 2011). Identification and delineation of important sites, processes, and questions for examination often proceed from an embodied knowledge of a city, or local literacy, that can be produced through observational walking and related techniques.

Geographers have increasingly focused attention on walking as an object of study because of its ubiquity and impact on urban experience (Edensor 2008, 2010; Middleton 2009; DeLyser and Sui 2013). Our aim is not to privilege walking but to call for more attention to (and reporting of) walking that urban researchers might already practice as both a precursor to and by-product of other ongoing research practices. Explicit attention to walking can also enable comparisons across cases and expose researchers' practices to peer review. If important moments of insight in urban geographic research are built on unreported (and potentially unreflective) data collection processes, it ultimately reduces the rigor of the research by obscuring the links between empirics and findings (Guba 1981; Denzin and Lincoln 2000). The data emerging from walking experiences can be made more reliable, and contribute to more insightful scholarship, through explicit reporting and methodological guidelines for consistent and comparable research methodologies.

Next, we trace the history of walking as method and acknowledge competing contemporary objections to walking as data collection. We then highlight how 
walking has shaped our knowledge of sites and questions in Pittsburgh, Pennsylvania, and Tshwane (formerly Pretoria), South Africa, although our reflections are informed by work more widely in the United States and South Africa. In juxtaposing our experiences, including limitations on our ability to walk within certain spaces, we highlight implications that walking has for the research process. This leads to a proposed framework for practicing and reporting on walking as method for urban geographers to increase its rigor and the ability to evaluate and compare reported findings.

\section{Walking as Urban Observation: A Methodological History}

We define observational walking for urban research as a self-conscious, reflective project of wandering around to better understand an area's physical context, social context, and the spatial practices of its residents. By walking we do not mean just the act of moving through the city on foot but also include related processes of standing, casual interaction, and observation. We draw on a well-established intellectual lineage in emphasizing walking in contrast to other means of moving in urban contexts (Anderson 2004; Blomley 2010; Edensor 2010; Middleton 2011). Certainly, facilitating pedestrianism is one of the core tasks of the built environment; although driving and biking are important modes of mobility, even late modern "car-centric" cities are working to include improved infrastructure that enables walking as a core mode of everyday circulation in areas of core density (Middleton 2011). Even disregarding walking's importance to urban development, however, observational walking helps researchers to develop local literacy, an embodied understanding of the scales and rhythms of an urban context that frame the data we collect in the form of interviews, focus groups, and so on.

Walking as method has a long history in urban scholarship. The flâneur-an (archetypically male) urban resident who wanders the city for sport, leisure, and personal understanding - has been often studied and nearly as often criticized (Benjamin [1940] 2007; Arendt [1968] 2007; Ibrahim 2008). Benjamin describes flâneurie (the project or process of walking and watching) as a curiosity-driven, open-ended process through which "true" patterns of human behavior can be observed over time and known. This 1800s archetype, drawn in contrast to the aimless attention of a gullible, thoughtless gawker, emphasizes the sharp and active mind of the wanderer and how understanding comes from being in, but not of, social interactions.

As late as the prewar period in the United States, urban and geographic analysis was often associated with a worldliness borne of such sharp-eyed observational experiences of the urban landscape (Simmel [1903] 1971; W. D. Jones and Sauer 1915). The quantitative analytical turn in U.S. urban theory from midcentury onward (Robinson 1950; Clark 1951), however, systematically depreciated the value of the personal insights of an urban stroller. Instead, scholars studying street life increasingly emphasized statistical approaches to analyzing the use of urban public space. Studies of walking (as an object of research) existed: Pedestrian versions of traffic analysis, these studies focused on rationalizing the collective behavior of walkers (Whyte 1980). Even when scholars valorized sidewalk life, however-most notably Jacobs ([1961] 1993)—walking as method was largely implicit or absent. As computers allowed for increasingly sophisticated aggregation of spatial data on demography, commuting, and transit utilization (Lipton 1980; Cropper 1981; Massey and Denton 1988), urban scholarship dependent on personal observations was marginalized.

There were, however, notable exceptions. There is an ethnographic side of the Chicago School's work in which participant observation is critical, often overlooked by geographers (Smith 1984). Yet even here, "the question of method was scarcely raised" (Smith 1984, 357). The midcentury work of the Situationists promoted walking as a means of radical psychogeographical engagement with the city, although their impact on geography has been limited (Pinder 1996; see Sinclair 1997; Bassett 2004). Similarly, Lefebvre (2004) offered a wideranging call for study of urban rhythms (including those of walking) that has not affected urban geographic research as much as his spatial triad or the notion of a right to the city.

\section{Walking as a Contemporary Research Object}

In the last decade, renewed attention to experiences of mobility in urban research (Latham and McCormack 2004; T. Cresswell 2006) has spawned two overlapping lines of inquiry about walking in geographic scholarship. The first explores how walking practices can be better incorporated into contemporary research as a method of learning from interviewees. Walking interviews that interact with a neighborhood context are used as a geographical-experiential prompt to provoke place-specific responses. Whether in one-on-one interviews (P. Jones et al. 2008) or touring focus groups (Inwood and Martin 2008), the goal of walking is to access experiences of interview participants.

Anderson $(2004,260)$, for example, noted, "the physiological movement of the body through place offers the opportunity to literally and metaphorically, "wander from plans to recollections to observations." He proposed that walking and talking with participants allows them to recall embodied experiences in ways that are difficult in a seated, more analytical environment. Describing his goals, he wrote:

For semi-structured interviews or participant observation [cultural practices] become the object of further 
questioning and/or inspection. With the co-ingredients of person-place in mind, however, it is important to supplement this literacy with an explicit awareness of the ways in which these practices are tied into places. Researchers can become aware of the key routines, habits and practices through which people inscribe their knowledges into places. (Anderson 2004, 257)

A second line of inquiry sees walking as an object of research (Wylie 2005; Murphy 2011; see Ingold and Vergunst [2008] in sociology). Middleton helps to frame our argument; whereas her earlier work focused on transcripts of walking experiences of urban residents as data (Middleton 2009, 2010), she recently argued that walking is also a subjective practice that needs study itself. She wrote (and we agree) that a "distinction might be drawn between transport research revolving around concerns with walking as a subject and much other work engaging with pedestrian practices drawing upon walking as a method" (Middleton 2011, 100). But where Middleton's interest in walking as subject is to explore dynamics of walking itself as an urban practice, we argue that walking as subjective experience is a part of the already-practiced arsenal of methods of many urban geographers.

Still, how researchers come to know the city is typically hidden even in reflections on walking as method and subject. Returning to Anderson's comments, we ask how researchers "become literate of ... cultural activities" and how they "become aware of ... routines, habits and practices." In primarily social or cultural research, scholars might situate this inductive process inside of early interviews, which (through iteration) become increasingly sophisticated, making the last interviews the most productively "literate" and context-aware (Marshall 1996). But in research that includes an interest in the spatiality of social practice, walking allows researchers to develop a spatial, local literacy that is specifically geographic.

\section{Walking as Method: Developing Local Literacy}

Anderson and others rightly highlight how walking interviews help us understand dimensions of participants' spatial experience that might otherwise be difficult to elicit. But what of the spatial experiences of the researcher? What should we do analytically with the sociospatial perceptions of researchers as they go about the urban spaces and places, the neighborhoods and cities about which they would like to draw conclusions?

Moles (2008), reflecting on her research on a public park, argued that walking as method "allowed me to really connect with the park; it allowed me to spend long amounts of time getting to know my research subject. It allowed me to experience the natural elements of the park at ground level, something discussed in the section below. It was a very 'natural' way of gathering data, something that emerged organically"
(5.1). She went on to describe this iterative, long-term process:

I walked where other people walked, and when they walked. I joined the power walkers at lunch time, and watched as they kept their heads down and earphones in. I saw commuters wearily wander to their cars, or make their way through the park to their post-work destinations. On weekends I saw people walking with no clear destination in mind, strolling along looking at the trees and flowers. Others sat in the park at the weekend, or ate picnics. By walking the same paths at different times I encountered different things, and saw the areas and spaces differently. At night, some places in the park were dangerous, and felt unwelcoming. (Moles 2008, 5.1)

We suggest that this description reflects a particular version of a not uncommon practice. Iteratively, with increasing confidence, she walked and observed so as to build an increasingly complex understanding of commuters, exercisers, passive users, and so on. She noted the temporality of their uses, and its rhythm over days, work weeks, and seasons. These insights, born of her walking experiences, help frame and understand subsequent interviews.

Edensor (2010) argued:

Through walking, a distinct embodied material and sociable "dwelling-in-motion" emerges ... as place is experienced as the predictable passing of familiar fixtures under the same and different conditions. But this may also emerge through a mindful passage across unfamiliar terrain through which the body adapts to land underfoot, and the peculiarities of place are apprehended. (70)

Walking in the city offers a key opportunity for observation at the spatial and temporal scales of the sidewalk's intended (as well as illicit) uses (Duneier 1999; Blomley 2010). Although Edensor acknowledged that the city has other infrastructure for other uses (e.g., highways and roadways for car commuting), he argued that "walking allow[s] for a particular experiential flow of successive moments of detachment and attachment, physical immersion and mental wandering, memory, recognition and strangeness" (70). Walking's insights are both important and difficult to replicate.

In geography and some adjacent disciplines (particularly anthropology), researchers' embodied experiences outside of formal interview processes are sometimes described as "ethnographic fieldwork" (J. Cresswell 2007). The term ethnography denotes long-term observational participation in a particular social or cultural context and would usually necessarily include some observational walking alongside of other modes of mobility (cf. Perramond 2001; Kotnik 2005). But although ethnographic methods might well include much of what we describe here as observational walking, our call 
is not for more walking (or more ethnography) per se. Rather, we call for systematic reporting of walking practices that researchers engage in (if and when they do), so that walking-derived insights can be evaluated-or their absence appropriately acknowledged - by reviewers and readers. Walking as method offers an opportunity to develop local literacy, but its most salient virtue is that it is difficult to engage in many forms of long-term urban research without it.

Over months of qualitative fieldwork, the time spent in interviews, focus groups, formal public meetings, and so on, can be measured in tens of hours. Scholars might spend many multiples of this time in their research contexts, but assessing typical patterns of researchers' walking is difficult, because semistructured urban exploration is not a widely reported method in the urban geographic literature. Certainly, embodied sociospatial experiences in a city or neighborhood spent in activities other than formal interviews or surveys likely affect findings. When scholars do engage in sustained personal observation, they should explicitly document the data collection, highlighting how it shaped other aspects of the research. Alternatively, the absence of such reporting might impact readers' evaluation of a project's validity and rigor.

\section{Problems with Walking: (In)validity and (Un)reflexivity}

Why does qualitatively oriented urban geographical research rarely foreground data derived from experiences moving around in the city? We suggest two simultaneous, and perhaps conflicting, critiques of methods like walking - one empiricist or positivist, the other poststructural and feminist- that might contribute to this hesitation. Although the combination of these critiques limits the scope of walking-supported claims, it does not necessarily demand an outright rejection of observational walking as a method. Both concerns must be addressed if walking is to be credibly acknowledged in a wider range of research.

The first concern, typically lodged from a quantitative empiricist perspective, is that observations made while walking are not rigorously sampled or subject to tests of reliability or validity (Bennett 1985; Richards 2004). This concern, not specific to observational walking, is magnified by the open-ended and sometimes unstructured way that researchers might go about the project of "being in" their study city (Leibing and McLean 2007). In this view, insights gained through observation while walking are not rigorous, cannot be verified, and thus should not be trusted.

In response to empiricist complaints, qualitative researchers have articulated evaluable standards of "good research" over the past thirty years (Lincoln and Guba 1985; Pyet 2003). Guba (1981) emphasized "trustworthiness" as a qualitative analog to quantitative rigor or internal validity. Morse et al. (2008) conversely insisted that rigor and validity as concepts are themselves perfectly compatible with a qualitative approach, noting that verification of rigor is not post hoc but rather the responsibility of researchers: It should be baked into their methodologies. In either case, the test of observational walking is not whether it produces data objects that another researcher can independently analyze but rather whether another researcher engaged in a similar process would develop similarly useful results (J. Cresswell 2007).

Reporting observational walking can thus be conceptualized as improving rigor both internally and externally. Internally, rigor is improved by making explicit the relationship among data, analysis, and findings (Guba 1981). Trustworthiness depends on our consistent reporting of these internal relationships and to the degree that researchers walk as method, the data they apprehend should be made visible to readers. In addition, external validity (e.g., replicability) depends on the ability of fellow researchers to reproduce findings from similar methods; where walking observations contribute to findings, it is a scholarly responsibility to report it in sufficient detail for colleagues to attempt to repeat it.

The second key concern about walking as method, grounded in poststructural and feminist literatures, is at cross-purposes to the first. Here, the concern is that researchers will make inappropriately generalized truth claims based on their specific perceptual experiences (Abu-Lughod 1999; Schuurman and Pratt 2002). Law (1999), for example, emphasized that although feminist-inspired scholarship on mobility has made female urban movement more visible (cf. Hanson and Pratt 1988), many reports on culture and mobility continue to elide women's experiences, generalizing a masculine researcher's experience. She did not argue for ignoring researchers' experiences but rather problematized privileging the "objective, universalizing voice" of the researcher (Foley 2002).

In fear of asserting ourselves too grandiosely as authors, however, we might have (as Latham [2003] noted) become overcommitted to "bringing back the data" (Thrift 2000), focusing on interview transcripts and other tightly constrained methods that safely place ourselves outside of the frame of research. Pratt (2000, 639) argued that qualitative geographers' "talk may be that of poststructuralists, postcolonialists, or social constructivists, but our practice continues to be that of colonising humanists." That is, by focusing on data that can be easily codified and eliding our participatory roles in the production of knowledge, qualitative scholarship might perpetuate a concept of data that Thrift (2000) called "timid."

The combination of these concerns-that observations are not reliable (in the statistical sense) and thus cannot be generalized and that experiences are dangerously totalizing (in the poststructural sense) and thus irresponsible-might seem to trap scholars. 
When considered carefully, though, they serve as cautions about what kinds of claims based on walking data can be responsibly admitted to the research process. In what follows, we propose that observations from walking can be used to inform other aspects of research, and thus incorporated into a research project that responds to concerns about statistical and positional validity.

\section{Everyday Walking as Geographic Method}

The iterative, ongoing nature of walking does not lend itself to systematic logging and transcript production: It would impede rather than clarify the analytic process to tabulate every trip to a grocery store, coffee shop, or library; every shared knowing look with a bystander waiting for a late bus; or each moment of tentative discovery as one passes a possible neighborhood transition (Leibing 2007; Chang 2008). Yet, experiences that cannot be incrementally counted can be reported and systematically compared. Key dimensions of observation (duration of stay, areas observed, degrees of observational saturation, synthetic comments about the questions produced) can, and we suggest should, be collated and reported. To promote comparative insights across cities and to ground initial observations in a replicable framework, Pierce developed a set of walking habits used when first arriving in a research area that has shaped work conducted in several U.S. cities. Our failed attempt to follow this pattern in Tshwane, however, provided the impetus for explicit reflection on how walking-and, conversely, not walking - shapes the research process. Here, we contrast the experiences of using this practice in Pittsburgh (Pierce) and Tshwane (together) and from this suggest wider implications of the impact of walking on research. This section is not intended to provide a complete framework but to demonstrate the impact of walking on subsequent research and articulate to specific methodological points that can be reported.

We propose, as a starting point, the following methodological steps.

\section{Start from a Location of Familiarity and Comfort}

Starting from a place of familiarity enables the researcher to relatively quickly get his or her feet on the ground, gain some level of confidence, and see emerging questions based on contrast with what is familiar. We typically begin by seeking out a city's university district(s), if present. This is essentially arbitrary, and a function of our own positionalities: As urban residents and scholars, we tend to be comfortable and recognize many analogues to cities we have previously called home. We situate ourselves and find points of reference for comparison: Is the university district tightly constrained or does it blend into surrounding neighborhoods? Do students seem comfortable? Is it more of a driving or a walking district?
Often, a university district becomes a provisional home base for urban exploration and a repeated point of departure.

Oakland, the neighborhood(s) between the University of Pittsburgh (Pitt) and Carnegie Mellon University $(\mathrm{CMU})$, includes a mix of large parks that are well-maintained, recently refurbished public plazas, and a busy commercial and restaurant corridor a bit worn around the edges that caters to students and university associates. Pitt and CMU are divided by a deep gorge that is crossed by a large bridge; this physical chasm seems to be both functional and symbolic. The city has other more isolated colleges and universities, but Oakland is the heart of the city's academic community.

In Tshwane, the main campus of the University of Pretoria (UP) is also near manicured parks and a bustling commercial and restaurant corridor (and a highincome residential neighborhood). The university is distinguished, however, by a 2-m-tall fence and access-controlled gates. Here, there is a strong contrast between the experience inside and outside of campus. Students are the main consumers in streetside fast-food restaurants where they appear to linger, but their presence is virtually absent from the public parks in the surrounding blocks. Car guards, unhoused youth, and buskers are the consistent faces purposively lingering in the commercial streets. Yet inside the gates, the campus evokes the open "public space" conjured in U.S. urban literature. This difference, only notable through iterative walking, prompted questions regarding the spatialities on and off campus. Surely the access-limited nature of campus makes UP private rather than public; yet, for many students the campus is a place-possibly their first place-for encountering extreme racial and socioeconomic difference.

\section{Focus on the Geography of Flows, Boundaries, and Connections}

After wandering around the universities, we tend to explore downtown. U.S. downtowns are diversely compact, with differences in the clarity of their street grids, their economic vibrancy, and the degree to which downtown is a cultural district. In Pittsburgh, downtown is a compact and walkable conjoining of two gridirons. It is constrained by rivers on two sides and steep inclines on a third, which shaped its historical development along with that of the rest of the city. As is true in much of Pittsburgh, the built environment seems disproportionately aging, with little new construction; although the office buildings are clearly still occupied, the overall sense is of underoccupancy and worn edges. The most important questions that emerged from Pierce's observational walking focused on boundaries with, and connections between, other neighborhoods. Pittsburgh's extensive riverfront and mountain topography mean that bridges are unusually prominent both in the visual appearance of the city 
and in its residents' mobility. Why do some bridges develop cultural cachet and others less so? Why do some bridges seem to strongly connect the neighborhoods on either side and others go less used? How do nonwater gorges and hills act differently as barriers than the city's famous rivers?

South African downtowns are also diverse. Whereas substantial investment has been made in the infrastructure, security apparatus, and symbolic status of downtown Johannesburg and Cape Town, Tshwane's downtown is characterized by crowded spaces, abandoned apartment buildings, and much street life, although with notably less street trade than in many urban centers in Africa. Once, we sought to catch a public taxi, a task Lawhon has often undertaken in other South African cities. Hailing a Tshwane taxi as two white pedestrians was considerably more challenging, however. This raised questions regarding the inside knowledge required to navigate the privatized semiformal mass transit and also the degree of racial separation in its transportation and neighborhoods.

Given safety concerns, exploring Tshwane's impoverished urban edge on foot proved difficult. Lawhon has explored South African townships in other cities but only with a locally knowledgeable guide. In Tshwane, we felt limited to driving past major townships along well-paved roads; our effort to enter through formal touring failed, as local guides responded to our inquiries months later. Although useful, even guided experiences restrict possibilities of serendipity, filtering the experience through the lens of a particular guide and limiting comparability. We suggest that the difference between initial experiences that are self-guided or guided by a resident, nongovernmental organization worker, or city official matter, and should be reported.

\section{Iterate Across Spatial and Temporal Boundaries}

Repeating the walk enables the researcher to understand patterns and assess the typicality of the observations. Over subsequent weeks or months, we typically seek to build an internal map of neighborhoods, extending from the places already visited and "saturating" (J. Cresswell 2007) notable areas with multiple return trips. We consciously try to revisit neighborhoods at different times of day: Is downtown at night busy or empty? Am I comfortable or not at 10 PM? Does the composition of people on the street change after rush hour? Do people run in the morning predawn?

In Pittsburgh, the iterations raised questions in two key domains. First, strikingly sharp social delineation between similar adjacent neighborhoods raised questions about the processes of neighborhood bounding in Pittsburgh and how they might differ from other places. Second, flow corridors (both for walking and for driving) are unusually well-defined, routing around Pittsburgh's steep terrain and rivers, leading to questions about the differences between Pittsburgh and other "steep cities" regarding mobility and transit flow.

In Tshwane, walking repeatedly helped us to better understand what we saw as well as to see patterns. We learned to distinguish kinds of waiting spaces: to differentiate the places to recruit informal laborers from the queue to enter the Department of Home Affairs or the parks where people lived from those where people lingered socially. By walking in different seasons, we saw how the jacaranda trees lining many streets change the urban aesthetic as well as the labor involved in sweeping up the fallen petals. Our repetitions were limited, however, as security concerns prevented us from walking in the dark, prompting reflection on our reliance on walking to understand temporal patterns.

The limitations of not walking as part of the research process were most clear in the moments when we felt constrained by safety or custom to avoid it. We were clear that the absence of walking made it more difficult to contextualize interview or media findings than in sites where we walked. This limited the probity of our questions about the use of space and our understanding of the inevitable elisions from our interview participants. In short, where we felt we could not walk, the kinds of research questions we were prepared to pursue were more tightly constrained. We acknowledge that even in the context of such constraints, researchers explore important questions but again call for recognizing their different origin.

\section{End with Questions, Not Answers}

We see walking as most useful in conjunction with other methods, typically not as an end in itself. Thus, we suggest the central goal of walking is to shape questions rather than support specific conclusions, requiring the researcher to further interrogate impressions generated from walking. In part, this is simply best practice qualitative research, emphasizing triangulation of analysis from multiple data sources (Baxter and Eyles 1999). But thinking of observational walking as a process of generating and refining questions rather than answers also holds us accountable to our limited, nonomniscient positionalities as researchers (Morse et al. 2008): It helps us check assumptions and the relevance of experiences to others in different positions and with different power relations (Guba 1981).

Over time, the questions developed in each city became more refined. Pierce developed specific sets of comparative neighborhoods that seem similar across multiple dimensions of income, ethnicity, and practice, yet seemed to differ along axes of regional investment and attitudes in the public discourse. In Tshwane, we are working on understanding different uses of space and how different kinds of boundaries shape willingness to engage with social difference in place. We expect these evolving question domains to shape future research through complementary 
methods, including spatial demographic analysis, interviews, focus groups, and participatory mapping.

\section{Toward Explicit, Comparative Walking Practice}

Walking has long contributed insights to qualitative urban research, helping us generate geographical questions informed by observation of the use of space over time that might not be easy to capture through other methods (Anderson 2004; Moles 2008; Edensor 2010). In particular, walking offers an opportunity for serendipitous discovery of unexpected contexts for social and spatial conjunction. It is particularly geographic among the ethnographic methods, offering an opportunity participate in the spatiality of everyday life of the city. Yet because urban geographers rarely highlight walking as a source of data, it is difficult to know whether walking is implicit or absent in texts reporting research findings. Thus, readers are unable to distinguish whether or not research is informed by walking, limiting their ability to evaluate its methodological rigor.

We suggest that if researchers are engaging in walking and thinking about the city, they should report these experiences. Reporting observational information helps communicate the researcher's positionality, acknowledging his or her context. If grounded, onthe-street experiences significantly shape research, scholarly peers should have the opportunity to evaluate those experiences and weigh the credibility of subsequent findings. This increases both the validity of the individual research reporting and the external validity of our collective research activities as we hone our walking methods in response to critique in scholarly discussion. Reporting walking when it occurs is also a positive response to the critique of Pratt (2000), affirming our scholarly acknowledgment of our complicated positions within, not outside of, the urban worlds we study.

Additionally, if researchers report the scope and nature of their walking experiences as practiced, we might begin to give differing credence to claims based on more or less extensive situatedness through walking. Further, not all walking practices are equal or equally observational. If researchers, for example, walk exclusively in spaces of consumption, or if they avoid areas of low density for reasons of aesthetic or convenience, those practices will shape the scope of potential insights. Our "timid" approach to methods like walking (Thrift 2000) might be obscuring the distinction between findings based on interviews and those that add hours of observational walking in a range of contexts to the process of saturation and triangulation.

Not all research must include walking to be valid or rigorous: Whether because of researchers' physical abilities, safety concerns, or appropriateness to a specific site, not every study will include observation via walking. Furthermore, urban researchers can find empirical saturation through nonwalking techniques; walking-generated data are not required to answer every urban research question. If walking is practiced, however, the scholarly audience should be able to evaluate the credibility of those data just as they would interviews or coding of news articles. Wider reporting of researchers' walking, when it is practiced, will make our collective scholarship more rigorous as it incorporates these experiences and materials that can substantively shape analysis.

\section{Funding}

Dr. Lawhon's research efforts were supported in part by a fellowship from the Urban Studies Foundation.

\section{Literature Cited}

Abu-Lughod, L. 1999. Veiled sentiments: Honor and poetry in a Bedouin society. Berkeley: University of California Press.

Anderson, J. 2004. Talking whilst walking: A geographical archaeology of knowledge. Area 36:254-61.

Arendt, H. [1968]2007. Introduction: Walter Benjamin, 1892-1940. In Illuminations, Walter Benjamin, 1-58. New York: Harcourt Brace.

Bassett, K. 2004. Walking as an aesthetic practice and a critical tool: Some psychogeographic experiments. Fournal of Geography in Higher Education 28:397-410.

Baxter, J., and J. Eyles. 1999. Prescription for research practice? Grounded theory in qualitative evaluation. Area 31:179-83.

Benjamin, W. [1940]2007. Illuminations, trans. H. Zohn. New York: Harcourt Brace.

Bennett, R. J. 1985. Quantification and relevance. In The future of geography, ed. R. J. Johnston, 211-24. London: Methuen.

Blomley, N. 2010. Rights of passage: Sidewalks and the regulation of public flow. London and New York: Routledge.

Chang, H. 2008. Autoethnography as method. Walnut Creek, CA: Left Coast Press.

Clark, C. 1951. Urban population densities. Fournal of the Royal Statistical Society Series A (General) 114:490-96.

Cresswell, J. 2007. Qualitative inquiry and research design: Choosing among five approaches. 2nd ed. Thousand Oaks, CA: Sage.

Cresswell, T. 2006. On the move: Mobility in the modern Western world. London and New York: Routledge.

Cropper, M. L. 1981. The value of urban amenities. Fournal of Regional Science 21:359-74.

DeLyser, D., and D. Sui. 2013. Crossing the qualitativequantitative divide II: Inventive approaches to big data, mobile methods, and rhythmanalysis. Progress in Human Geography 37:293-305.

Denzin, N. K., and Y. S. Lincoln. 2000. The discipline and practice of qualitative research. In Handbook of qualitative research, ed. N. Denzin and L. Lincoln, 1-28. Thousand Oaks, CA: Sage.

Duneier, M. 1999. Sidewalk. New York: Farrar, Straus and Giroux.

Edensor, T. 2008. Mundane hauntings: Commuting through the phantasmagoric working class spaces of Manchester, England. Cultural Geographies 15:313-33.

. 2010. Walking in rhythms: Place, regulation, style and the flow of experience. Visual Studies 25:69-79. 
Foley, D. 2002. Critical ethnography: The reflexive turn. International fournal of Qualitative Studies in Education 15:469-90.

Guba, E. 1981. Criteria for assessing the trustworthiness of naturalistic inquiries. Educational Technology Research and Development 29:75-91.

Hanson, S., and G. Pratt. 1988. Reconceptualizing the links between home and work in urban geography. Economic Geography 64:299-321.

Ibrahim, A. 2008. The new flaneur. Cultural Studies 22:234-53.

Ingold, T., and J. L. Vergunst, eds. 2008. Ways of walking: Ethnography and practice on foot. Anthropological studies of creativity and perception. Aldershot, UK: Ashgate.

Inwood, J., and D. G. Martin. 2008. Whitewash: White privilege and racialized landscapes at UGA. Social \& Cultural Geography 9:373-95.

Jacobs, J. [1961] 1993. The death and life of great American cities. New York: The Modern Library.

Jones, P., G. Bunce, J. Evans, H. Gibbs, and J. R. Hein. 2008. Exploring space and place with walking interviews. Fournal of Research Practice 4:D2.

Jones, W. D., and C. Sauer. 1915. Outline for field work in geography. Bulletin of the American Geographical Society 47:520-25.

Kotnik, T. 2005. The mirrored public: Architecture and gender relationship in Yemen. Space and Culture 8:472-83.

Latham, A. 2003. Research, performance, and doing human geography: Some reflections on the diary-photograph, diary-interview method. Environment and Planning $A$ 35:1993-2017.

Latham, A., and D. McCormack. 2004. Moving cities: Rethinking the materialities of urban geographies. Progress in Human Geography 28:701-24.

Law, R. 1999. Beyond "women and transport": Towards new geographies of gender and daily mobility. Progress in Human Geography 23:567-88.

Lefebvre, H. 2004. Rhythmanalysis: Space, time and everyday life. London: Continuum.

Leibing, A. 2007. The hidden side of the moon, or "lifting out" in ethnographies. In The shadow side of fieldwork: Exploring the blurred borders between ethnography and life, ed. A. McLean and A. Leibing, 128-56. Malden, MA: Blackwell.

Leibing, A., and A. McLean. 2007. "Learn to value your shadow!" An introduction to the margins of fieldwork. In The shadow side of fieldwork: Exploring the blurred borders between ethnography and life, ed. A. McLean and A. Leibing, 1-28. Malden, MA: Blackwell.

Lincoln, Y. S., and E. Guba. 1985. Naturalistic inquiry. Beverly Hills, CA: Sage.

Linstead, S. 1993. From postmodern anthropology to deconstructive ethnography. Human Relations 46:97-120.

Lipton, S. G. 1980. The future central city: Gentrified or abandoned? Fournal of Urban Affairs 2:1-15.

Marshall, M. 1996. Sampling for qualitative research. Family Practice 13:522-25.

Massey, D., and N. Denton, 1988. Suburbanization and segregation in US metropolitan areas. American fournal of Sociology 94:592-626.

Middleton, J. 2009. "Stepping in time": Walking, time, and space in the city. Environment and Planning A 41:1943-61.
2010. Sense and the city: Exploring the embodied geographies of urban walking. Social and Cultural Geography 11:575-96.

—. 2011. Walking in the city: The geographies of everyday pedestrian practices. Geography Compass 5:90-105.

Moles, K. 2008. A walk in thirdspace: Place, methods and walking. Sociological Research Online 13:1-12.

Morse, J., M. Barrett, M. Mayan, K. Olson, and J. Spiers. 2008. Verification strategies for establishing reliability and validity in qualitative research. International fournal of Qualitative Methods 1:13-22.

Murphy, J. 2011. From place to exile. Transactions of the Institute of British Geographers 36:473-78.

Perramond, E. 2001. Oral histories and partial truths in Mexico. Geographical Review 91:151-57.

Pinder, D. 1996. Subverting cartography: The situationists and maps of the city. Environment and Planning $A 28$ (3): 405-27.

Pratt, G. 2000. Research performances. Environment and Planning D: Society and Space 18:639-51.

Pyet, P. 2003. Validation of qualitative research in the "real world." Qualitative Health Research 13:1170-79.

Richards, L. 2004. Qualitative software meets qualitative marketing: Are these tools the right tools? In Applying qualitative methods to marketing management research, ed. $\mathrm{R}$. Buber, J. Gadner, and L. Richards, 32-45. Houndmills, UK: Palgrave Macmillan.

Robinson, W. 1950. Ecological correlations and the behavior of individuals. American Sociological Review 15:351-57.

Schuurman, N., and G. Pratt. 2002. Care of the subject: Feminism and critiques of GIS. Gender 9:291-99.

Simmel, G. [1903] 1971. The metropolis and mental life. In On individuality and social forms, ed. D. Levine. Chicago: University of Chicago Press.

Sinclair, I. 1997. Lights out for the territory. London: Granta Books.

Smith, S. J. 1984. Practicing humanistic geography. Annals of the Association of American Geographers 74 (3): 353-74.

Thrift, N. 2000. Dead or alive? In Cultural turns/geographical turns: Perspectives on cultural geography, ed. I. Cook, D. Crouch, S. Naylor, and J. Ryan, 1-6. Harlow, UK: Prentice-Hall.

Whyte, W. 1980. The social life of small urban spaces. Washington, DC: The Conservation Foundation.

Wylie, J. 2005. A single day's walking: Narrating self and landscape on the South West Coast Path. Transactions of the Institute of British Geographers 30 (2): 234-47. 